infants and girls who were lodged upon the same side of the school premises.

The disease having declared itself so definitely among a particular group of inmates, it was deemed advisable to quarantine those not yet affected. Hence, school attendance was done away with for the time being, and the children sent into the fields as much as possible; a lavatory was appropriated to their exclusive use, and towels were changed upon each occasion of washing. In a word, the in mates of $\mathrm{D} 6$ were not suffered to come into any sort of contact with the rest of the school.

The attendants were warned as to the nature of the disease, and told to notify me immediately the least sign of discharge or redness was noticed in any eye. A special observation ward was got ready in the Ophthalmic School, to which any suspicious case might be sent without an instant's delay. Directions were given that the bedding, towels, etc., of any infected child should go to the steam disinfector, and also that his bedstead should be carbolised. Lastly, the "babies" were examined by me twice a day.

It is most instructive to trace the further course of the malady. On April 15th 3 and on April 16th 6 more cases were detected among the children of D6. On the latter day another lad (J. R.) was taken from the infirmary, to which he had been sent twenty-four hours previously for some general ailment. On April 17th 3 and on April 18 th 2 other children were taken from D6. On April 19th the 2 remaining infants were found to have contracted the disorder, and were forthwith separated. In fact ophthalmia had made a clean sweep of the infants of the ward, for the only inmates who remained unaffected were two schoolgirls who helped in the dormitory work. Presumably they escaped owing to the fact that at their age they had naturally less tendency to contract disease than the infants, who from their habits are particularly prone to spread infection from one to the other. Furthermore, one older lad (E. M.) had been separated. The total thus far affected was therefore 23

On April igth a suspicious case (E. W.) was found among the " baby girls," who, as already stated, occupied a ward on the same floor as D6. The child was sent to the Ophthalmic School. On the following day another " baby girl" (J. G.) developed the disease, and was isolated without loss of time.

The ward occupied by these "baby girls" was known as D5. It was, save in size, similar in all essential points to D6, and hence need not be described in detail, further than to say that its length was 67.25 feet, its width 18 feet, and its height 12.25 feet. At the time of these occurrences it contained 30 children, of whom 28 were infants and 2 ward girls. Upon the 36 feet super basis, then, there was no overcrowding.

As I feared that the disease might spread among the children of this dormitory, as it had among those of D6, the whole of the "baby girls," with their beds and bedding, were sent to a detached building that lay upwards of roo yards from the main school, where they were strictly quarantined. The two ward girls went with them, as did also the two who had remained unaffected in D6.

The wards thus vacated by the removal of children were fumigated with sulphur and then thrown freely open to the air. Their walls and ceilings were washed and re-distempered. The floors were scrubbed, and afterwards polished with beeswax and turpentine. An opportunity was also taken of disdisinfecting, cleansing, and redecorating the attached lavatory.

Judged in the light of after-events, the entire separation of those belonging to $D_{5}$ had a happy result. Thus, they were kept apart from April 2oth to April 3oth, yet during those ten days no fresh case was found among them.

We may sum up the facts as follows: Between April 12th and April 25th, 25 children became affected with acute mucopurulent ophthaimia. Of that number, 22 came directly or indirectly from a single ward. and the other 3 from dormitories more or less closely connected with it.

In conclusion, I think it important to state clearly that this is the only outbreak of acute ophthalmia that has taken place in the Central London District School during the last six years. That the recent cases were not of a serious nature will be evident from the facts $(a)$ that those affected are now convalescent : (b) that in no single instance was the cornea involved; and (c) that no sequelæ have developed.

[Besides the foregoing, ro girls and 2 boys were sent from the school to the observation ward between April 18th and April 24th, 1896. These children were removed simply as a measure of precaution. Most proved to be instances of phlyctenular conjunctivitis or of episcleritis, but a few were of anomalous nature. Not a single one suffered from mucopurulent ophthalmia.]

\section{NOTES ON A CASE OF ACROMEGALY.}

$$
\begin{aligned}
& \text { R. ROXBURGH, M.B., and A. J. COLLIS, M.B., } \\
& \text { F.R.C.S.Edin., }
\end{aligned}
$$

Weston-super-Mare.

THE aggregation of clinical phenomena, which received from Marie the designation of " acromegaly," though constituting a well-recognised pathological entity, still belongs to the rarities of medical observation, and as post-mortem examinations of cases have been rarer still, the following example may be of interest.

Mrs. M., aged 35, lived in Scotland till just before her marriage at the age of 19 , and from then till the time of her death at Weston-super-Mare. 'There is no history of a similar complaint in the family, and the family history is good. The mother is living and healthy, aged 6o; the father died in India (cause unknown). The patient had had no previous illness of any importance except variola at the age of ${ }_{3} 3$. She had six children in nine years, all of whom are alive and healthy. The last was born seven years ago, and from that time (when aged 28) menstruation ceased entirely.

Six or seven years ago she observed that her hands and feet were getting larger, and five times over she required to have her rings filed off her fingers and made of an increased size. She had to have boots specially made to order during the last three years. Her friends noticed a great alteration in her appearance, and say that her nose grew bigger. No photograph of her as a younger woman is obtainable. She seems to have first come under medical observation in May, 1893, when she complained of failing sight. Double optic neuritis was then found, but no cause was assigned. The size of the hands and feet does not seem to have been such as to attract attention at that time.

The case first came to our notice in December, 1894, when the appearances were those generally associated with this malady-large and ponderous hands and feet, heavy and thickened features, the nose especially so, prominent frontal eminences, the skin of the face and neck coarse and thick. Her weight was I 5 stone, though she was not corpulent; two years previously she weighed a little over 13 stone. Her general appearance was anæmic. The enlargement was clearly due to bony growth and not to any subcutaneous deposit. The lower jaw was noticeably thickened, giving the face the ovoid form with the broad diameter downwards which is characteristic. The heart was normal, and the thyroid and spleen presented no increase of size. Constipation was troublesome, and she complained of indigestion and frequently of great thirst; double optic atrophy was present. Owing to various circumstances little was seen of the case till July, 1895, when it was found that the amaurosis had advanced to a condition of total blindness in the left eye and well-marked hemianopia in the right, the nasal half of the field of vision being defective. She complained at this time of occasional headaches and pains in the lower limbs. Towards the end of July she fell into a very drowsy condition lasting about a fortnight, so that she was unable to do her work. One day she was found asleep on the stairs, and when aroused said she had gone to sleep unintentionally whilst going up. She frequently went to sleep whilst being spoken to. This period of drowsiness was followed by a persistent headache, which remained till her death on September 2rst. When this headache first came on, it was very severe and prevented her sleeping; she took to her bed, and lay groaning day and night unless relieved by morphine injections. Sulphonal, phenacetin, potassium iodide, arsenic, and cannabis indica gave no relfef. During the last week in August 
the headache became easier and she became drowsy again. Up to September and she had been able to count fingers held in front of the face, but on this day she could not, and about this time she also lost the sense of taste completely. On September gth she could not distinguish a strong light held in front of the eye. The urine then and throughout contained no albumen or sugar. On September i2th she began to pass motions and urine involuntarily. On September 1 3 th, when she was moved out of bed into an armchair for a short time, it was noticed that she could stand, and that there was good movement of the lower limbs. No interference with motor or sensory (spinal) conduction was observable, indeed, during the progress of the case. Whilst standing she kept her head very much retracted; she did not keep it so whilst lying down. There was no marked kyphosis. The temperature, taken at irregular intérvals, was always found to be subnormal. Her memory for recent events was very bad, but it remained good for events in her early life. On Septem-

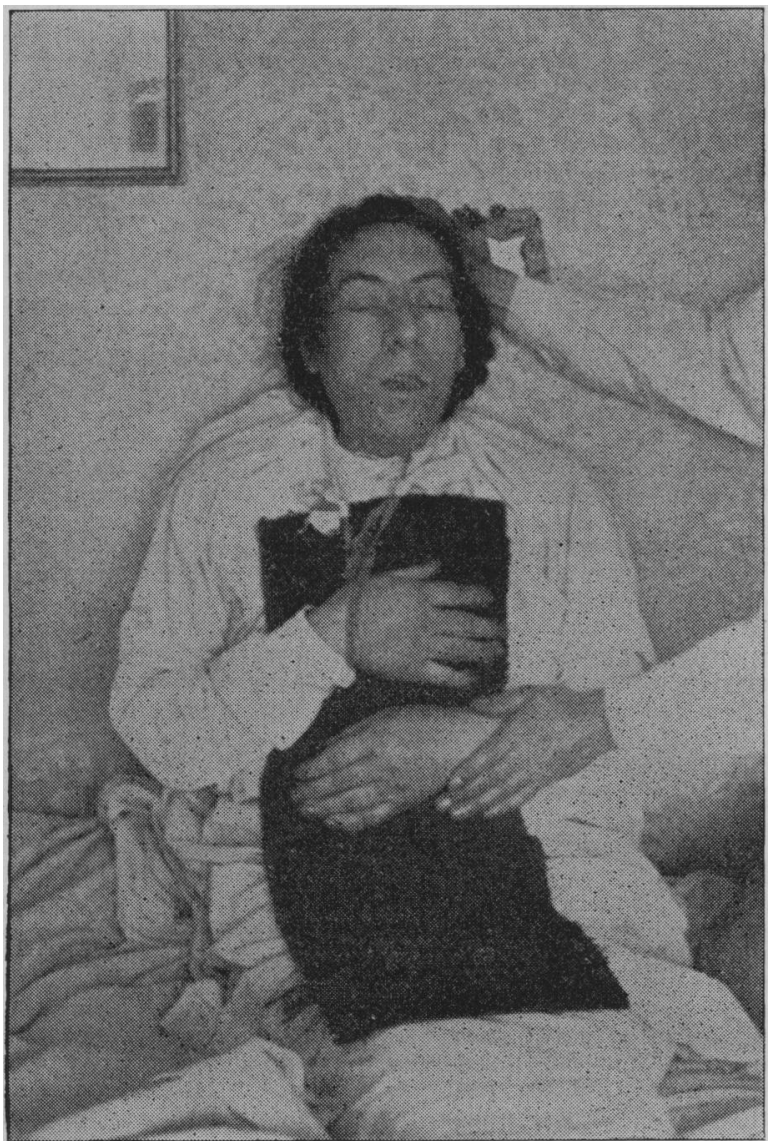

ber 21st, at noon, she was found to be in a deep sleep; she could be roused to answer questions briefly, but went to sleep again at once. During the afternoon she could no longer be roused, and died in a comatose condition in the evening.

At the necropsy, made forty-three hours after death, the body presented a well-nourished condition. On opening the thorax we found a large thymus gland, measuring $3 \frac{1}{2}$ inches long and an inch and a-half wide, the two lobes extending upwards above the sternum for half an inch, and the lower part of the gland extending to the level of the upper border of the third rib. In its general shape and appearance it resembled that of the child. The thyroid gland was normal. On opening the skull the tables were found to be of normal thickness and density, but the frontal sinuses were markedly enlarged. Some signs of local meningitis existed at the vertex in the form of adhesions and recent patches of lymph. The pituitary body, which was the size of a walnut, was very soft and vascular. The dura mater of the sella turcica had entirely disappeared, and the bone here presented an irregularly eroded and vascular appearance. The irregularities were filled with extensions of the pituitary growth. The mass had so pressed upon both optic tracts and the chiasma as to cause total disappearance of the left tract and partial destruction of the right. On the left side of the mass there was a blood clot the size of a large pea.

In other respects the brain showed no abnormality. The spleen was enlarged, measuring $7 \frac{1}{2}$ by 4 inches. Both kidneys were large, and the capsules slightly adherent. Other organs were normal. The feet and hands were greatly enlarged, and of a clumsy contour. The accompanying illustration, taken after death, shows the hands so arranged as to contrast with the normal-sized hands of one of the writers, who supported the body. Detailed measurements were not taken The ribs and clavicles were not noticeably hypertrophied. Microscopically the thymus was found to be of normal structure, Hassall's corpuscles being numerous.

The pituitary tumour was of such soft and friable consistence that its removal and subsequent preparation were matters of considerable difficulty. It was impossible to differentiate two lobes of definite character. Most of the mass had the microscopic appearances of hypertrophy of the normal posterior lobe, but the peripheral, and especially basal, portions presented characters midway between those of a

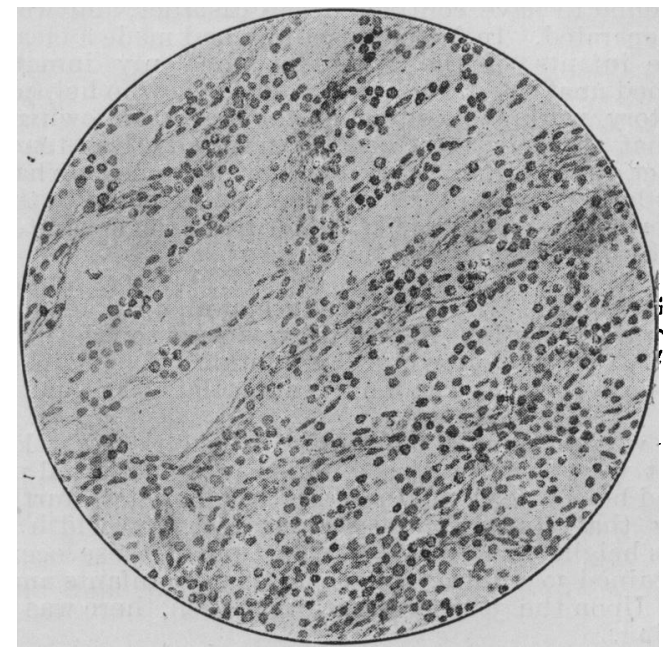

Microscopic section of the pituitary tumour.

glioma and of a round-celled sarcoma ; rapidly proliferating small cells-chiefly round, and a few spindle-shaped-being interwoven by fineconnective tissue bundles. Where cell growth was abundant, the protoplasm was sparse and the rounded nuclei were crowded together with little or no intercellular tissue. Especially was this the case where the bone was eroded, Howship's lacunæ being crowded with dense cell growth. In other parts the cells were more scattered and their protoplasm was more defined. In parts, too, the intercellular bundles had undergone a colloid change, so that the cell elements were barely held together. These characteristics are shown in the accompanying illustration (drawn by the Clinical Research Association) from one of our sections stained with hæmatoxylon. It is not easy to say whether the tumour should more accurately be described as a glioma or a sarcoma. Undoubtedly its medullary character and destructive action on the bone sufficiently demonstrate its local malignancy, although the absence of metastases deprives it of an infective character.

It cannot be said that this case throws such light on the pathogenesis of the malady as definitely to decide the question how far the enlarged hypophysis cerebri is a cause, how

1 Exhaustive measurements in other cases will be found in the paper on Acromegaly by Professor Julius Arnold, in Virchow's Archive i ited. 
far a symptomatic concomitant of the other clinical features. For the premature cessation of the menses and the changes in the hands and feet began seven years ago, while pressure eymptoms and optic atrophy were not complainea of till four years later. The case, however, adds one more to the examples, already sufficient in number, which prove at least the striking coexistence of an enlarged pituitary body with the other phenomena of acromegaly.

\section{PRESIDENTIAL ADDRESSES}

DELIVERED AT THE ANNUAL MEETINGS OF THE BRANCHES OF TIIE

\section{BRITISH MEDICAL ASSOCIATION.}

\section{SOME POINTS AT ISSUE BETWEEN THE PUBLIC AND THE PROFESSION.}

\section{Delivered at a Combined Meeting of the East Anglian and} Cambridge and Huntingdon Branches at Dersingham, June 18th, 1896.

By A. R. MANBY, M.D.,

Surgeon-Apothecary to the Prince and Princess of Wales at Sandringham; President of the East Anglian Branch.

IT had been my desire, if the weather permitted, in consideration of the exceptional privilege accorded to us by the gracious permission of their Royal Highnesses to wander about the lovely grounds of Sandringham, that we should dispense with business and take full advantage of the treat allowed us; but the arbiters of fate in the shape of the tyrannical secretaries of the Branch, Drs. Beverley, Barnes, and Carr, have decided otherwise, for they say that the whole raison d'être of our meeting is business, and play must take a very secondary place, or we shall risk the wrecking of the articles of incorporation of the British Medical Association; at least they do not say quite that, but I have reason to know that when a non possumus is desirable or necessary the method of obtaining it is always the citation of that excuse. I confess, too, to a lingering, perhaps sneaking, hope that by so doing I might be saved the preparation of, and you the pain of hearing, the poor apology for the address which heretofore has always been delivered with so much brilliance by the galaxy of orators who have preceded me in your honourable chair. Honourable truly, for I can conceive of no greater honour than that of presiding at so full a meeting of one's own professional neighbours, who must always be the best judges, as they are the keenest critics, of a man's abilities. Indeed a tale I once heard of Sir Henry Thompson (who is, by the way, an East Anglian) in his youth shows that I am not singular in my conception. He is said to have boasted to his relations and fellow-students that he intended to be well spoken of " not only by the public," but by the members of his own calling, and how thoroughly he has kept his intention is simple history. This has always acted as a hint to me as to what summit to struggle for, and while I gratefully accept from you the honour of its attainment, I can only wish it had been more worthily deserved. It has always seemed to me that the preparation of an address by such a man as myself would be a difficult and useless labour; a specialist, devoting his life to one subject, a scientist studying a particular branch and achieving distinction therein, would have a far easier task, a chapter at random out of, or a précis of, his latest book being all-sufficient and certain of success and attention; but not so the drivellings of a country general practitioner who lives in his great coat and sleeps in his gig, being at the same time general practitioner and Jack of all specialities, ready at all times to struggle with death, or what is often more difficult, deformity, perhaps in a cottage alone with a solitary candle and a fainting Mrs. Harris, cutting a hernia or setting a compound fracture, sweating with fright at an unexpected inversion of uterus, or some other delightful development of the so-called "natural labour," which is so easy to legislate for and so difficult to define, for how seldom can we prognose an unnatural one? Or he may have alone to aspirate a pleurisy, nurse a pneumonia, open an empyema, remove an eyeball or cataract or stone, to incise a tympanum, to draw a tooth; or by way of a change to tracheotomise a diphtheria, to tap a dropsy, to remove foreign bodies from each or every orifice of the body, to apply antitoxic serum and other new remedies $v i$ et armis, and to risk health and life, or the still dearer reputation, at all or any hour of the twenty-four, uncertain whether any consecutive twenty minutes will be his own; on duty not for an eighthour day or for six days a week, but twenty-four hours out of every twenty-four hours and seven days a week. How can he study? How can he advance science? How can he attempt perfection? How can he write an address? Gentlemen, is my apology sufficient? May I stop? May we abandon work and enjoy the lovely walks and spectacles hereabout, or must I further bore you? If so I will proceed, but with a big "but." But if a country general practitioner cannot be scientific or learned, he can be interested in many subjects which affect his own welfare and that of the whole body of his professional brethren, the quasi politics of the profession. And as your unworthy, and for the last year I humbly confess, also neglectful, representative on the Parliamentary Bills Committee of the British Medical Association, it seems to me fitting that I should glance shortly at a few of our most urgent questions.

There is the ever-pressing subject of fees, as of Poor-law salaries and extras, club remuneration, police, coroners' and assize courts. And here I would pay a passing tribute to the memory of one who has gone from us, all too soon for those he has left to mourn him, and who, as honest as impetuous, was ever eager to improve and maintain the dignity of the medical profession, especially in this connection. I mean poor Vincent, of Dereham, whose early death we must all deplore, and who never forgot to remind me that my office was valuable as a means to the end of impressing on the Legislature the value of a doctor's time-an opinion which I fully shared but have been unable hitherto to further, but which I hope some worthier representative will be able to press; especially in the matter of magistrates' courts, where I find that recently an order has been given that only 10s. $6 \mathrm{~d}$. shall be allowable as fee plus the allowance for distance-an absurdly inadequate fee when, as in my own case, the nearest petty sessional court is seven miles distant, and a half-day at least must be occupied to enable me to attend.

Assize courts are not so bad, although in them the fee might easily be trebled, and even then the expense to the county diminished if more care was taken to subpœna the medical witness only for the day on which he was likely to be called, and not for the whole assize. I remember my first attendance at Norwich Assizes. Over-impressed with the majesty of the law, I was.in attendance, on the first day, hours before the fanfaronade of trumpets announced the approaching pomp, to find my case called the same evening, and the prisoner-a poor little girl-pleading guilty with many sighs and tears; for some reason no doubt sufficient to the legal mind, she was persuaded to withdraw her plea, and I waited, waited, waited all so wearily throughout the whole week until quite the end, and until she was again put into the dock, the very last case of an extra long assize, and sentenced to a month without hard labour. I am not quite certain, but I believe I received, with railway fees, some $f^{6}$ more than I need have done had the original allowance been trebly large, and I only called the last day, when I was wanted.

Poor-law fees are notoriously bad; and the public gain by our want of professional cohesion, for in its early days, or rather before its inception, each parish used to maintain and pay liberally for its own poor, and the work was well done and the appointment coveted, so much so that, just as now medical aid associations have developed out of the semi-charitable clubs, so then the greedy public saw how to make capital out of them, and by dividing the country into districts large enough to make a nucleus for a practice, was enabled to drive down the contract price to the lowest ebb; but that is not all ; my salary as district parish officer amounts to nearly double my blacksmith's bill for horseshoes, and yet I pay income tax under Schedule $E$ on the total, as if it were all profit. Extra fees are an occasional godsend; a hernia, a broken bone, provided it is not a 